\title{
Pervasive fluid flow in subducted crust
} PROF. DANIELA RUBATTO ${ }^{1,2}$, THOMAS BOVAY $^{3}$ AND
PIERRE LANARI ${ }^{3}$

${ }^{1}$ University of Bern, Institute of Geological Sciences

${ }^{2}$ University of Lausanne

${ }^{3}$ University of Bern

Presenting Author: daniela.rubatto@geo.unibe.ch

Dehydration reactions in the subducting slab liberate fluids causing major changes in rock density, volume and permeability. Although it is well known that these fluids can migrate and interact with the surrounding rocks, fluid pathways remain challenging to track and the consequences of fluid-rock interactions processes are often overlooked. We investigate pervasive fluid-rock interaction in a sequence of schists and mafic felses within meta-ophiolites of the Zermatt-Saas Zone (Western Alps), which reached eclogite-facies conditions during Alpine convergence. Chemical mapping and in situ oxygen isotope analyses of garnet from numerous schists reveal a sharp chemical zoning between a xenomorphic core and a euhedral rim, associated to a drop of $\sim 8 \%$ in $\delta^{18} \mathrm{O}$. Thermodynamic and $\delta^{18} \mathrm{O}$ models show that the large amount of low $\delta^{18} \mathrm{O} \mathrm{H}_{2} \mathrm{O}$ required to change the reactive bulk $\delta^{18} \mathrm{O}$ composition cannot be produced by dehydration of the mafic fels, and requires contribution of fluids from the surrounding serpentinites. The calculated time-integrated fluid flux across the TGU rocks is 1.1 $\mathrm{x} 10^{5} \mathrm{~cm}^{3} / \mathrm{cm}^{2}$, which is above the open-system behaviour threshold and argues for pervasive fluid flow at high-pressure conditions. The transient rock volume variations caused by lawsonite breakdown in the schists is identified as a possible trigger for the pervasive fluid influx. The schist permeability at eclogite-facies conditions $\left(\sim 2 \times 10^{-20} \mathrm{~m}^{2}\right)$ is comparable to the permeability determined experimentally for blueschist and serpentinite. This study demonstrates that high permeability and fluid flow can be pervasive at high-pressure conditions, and do not necessarily require channelization in veins or shear zones. 